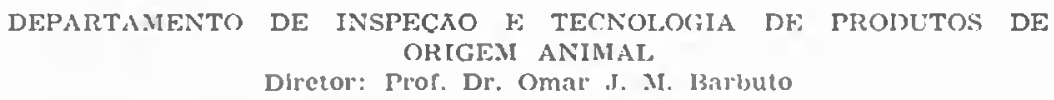

\title{
CONTRIBUIÇÃO PARA O ESTUDO DA INCIDÊNCIA DE GERMES DOS GRUPOS COLIFORME E ENTEROCOCO NO LEITE E EM ALGUNS DE SEUS DERIVADOS *
}

(INCIDINCE OF COIIFORM AND FNTEROCOCCI MICROORGANISMS IN MILK DAIRY PIODICTS

\author{
Jose Chzar Paximta
}

Instrutor

\section{INTRODUCAXO}

Tão sòmente ao se publicarem trabalhos acêrca de microrganismos que fermentavam a lactose (PARASTIRIU; PIRESCOTT; Winslow \& Walker; Fromme; Rogers; Clark \& Evans, citados por Allen

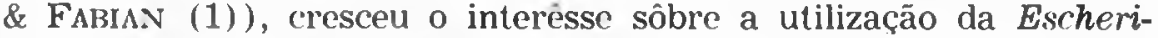
chia coli como um germe teste para se constatar a qualidade sanitária da água e dos alimentos manipulados. Embora a $E$. coli fôsse mais fàcilmente isolada, comparativamente aos outros germes entéricos, a ocorrência de formas intermediárias e de espécies atipicas, além de sua patente semelhança com outros gêneros da família Enterobacteriaceae (Klebsiella, Arizona, Achromobacter, etc.), fizeram com que se abandonasse parcialmente a pesquisa exclusiva dêsse microrganismo como indicador de poluição fecal. Estabeleceu-se, então, um grupo representativo que inclui êsse germe como protótipo, ao qual foi dada uma multiplicidade de designações (B. coli, E. coli, "cólon", coli-aerogenes, Eschericia-Aerobacter) e que BREED \& NOR'TON (6) denominaram de coliforme.

Desde então, êsses microrganismos foram considerados como aptos a revelar a poluição fecal da água, do leite e também de outros alimentos. Na realidade, a maior parte dos Regulamentos de Inspeção Sanitária, ao preconizar normas para se aquilatar o grau de contaminação dos alimentos, sugere a pesquisa do número de coliformes néles existentes ,3, 5, 14, 35).

- Apresentado a Faculdade de Mediclna Veterinária da Universidade de Săo Paulo c aprovado para a obtencāo do título de Mestre. A anállse estatística dos resultados deveu-se à cooperaç̄o do Departamento de Illgiene, Saúde Pública e Bioestatistica, da Faculdadc de Medicina Veterinária dil Universldade de São Paulo. 
Entretanto, como resultado de mais de meio século de estudos, o significado do grupo coliforme como teste sanitário, tem sido bastante modificado. O advento de novos meios de cultura e de técnicas mais acuradas, demonstraram que êsses fermentadores de lactose constituiam um grupo evidentemente heterogêneo, que compreendia muitos germes de "habitat" não exclusivamente intestinal e de duvidoso significado sanitário. Efetivamente, RoGers, Clark \& Evans (citados por Allen \& FABIAN (1)) afirmaram que bactérias idênticas às do tipo "cólon", apareciam freqüentemente em frutas, cereais, gramíneas e no próprio solo, fato que comprometia sèriamente a eficiência do grupo na indicação de poluiçāo fecal, pois, embora os germes nêle classificados mantivessem a propriedade geral de fermentar a lactose com produção de gás, era possivel dividi-los em subgrupos cujos representantes podiam ter como "habitat" o intestino do homem e dos animais ou, também, o solo, os cereais, os frutos e as gramíneas. Para complicar ainda mais o quadro, constatou-se que algumas bactérias esporogênicas e leveduras, abundantemente encontradas na natureza, também possuíam a capacidade de fermentar a lactose e produzir gás.

Mais tarde, o estabelecimento de meios de cultura diferenciais entre os germes que compōem o grupo coliforme, veio trazer menor risco à utilização dêsses microrganismos. Assim, Escherichia coli algumas vêzes e coliformes de modo geral, passaram a ser usados para a comprovação da qualidade sanitária dos alimentos, tendo-se em vista, entre outros fatôres, a predominância dêsses germes nas fezes humanas e os métodos relativamente simples para a sua evidenciação nos produtos elaborados.

Ainda que o significado dos estreptococos fecais como organismos indicadores de poluição, não tenha sido estabelecido para a água e outros alimentos com a mesma definibilidade que marca o conhecimento do grupo coliforme, êles têm sido isolados tão frequientemente de fontes poluidas por fezes e das próprias fezes que parece razoável encarar a sua presença como indicadora de poluição fecal, uma vez que são raramente detectados em alimentos normais. Originalmente assinalada por LAWS \& ANDREWS (cit. ALLEN \& FABIAN (1)), sua importância não foi salientada senão quando HoustoN (cit. Alle.v \& Fabian (1)) chamou especial atençāo sôbre o fato de que estreptococos e estafilococos pareciam ser característicos de esgotos e dejetos animais. Os próprios LAws \& ANDREws acreditaram que eram mais verdadeiramente indicativos de poluição perigosa, uma vez que eram ràpidamente demonstrados em águas recentemente poluidas.

Mas, ainda que um teste coli-aerogenes positivo represente indicação segura de contaminação fecal em potencial, um resultado negativo não prova ausência de contaminação, pois tem sido de- 
monstrado repetidas vêzes que bactérias coli-aerogenes são relativamente sensiveis às condiçōes desfavoráveis do meio, podendo morrer antes dos micróbios enteropatogênicos (KELLY \& ARCISZ (18)), além de que a $E$. coli pode, às vêzes, ocorrer nas fezes em número extremamente pequeno (BorneFF, cit. Mossel, VAN DIEPEN \& BRUIN (25)).

Éstes, entre outros, são fatôres que levaram à procura de diferentes indicadores de poluição fecal, dentre os quais os estreptococos fecais, os quais parecem realmente üteis como microrganismos testes da qualidade bacteriológica dos alimentos, tendo $\mathrm{cm}$ vista, principalmente, a sua resistência nos produtos (ALLEN \& FABIAN (1, 2); BRown \& GibBons (7); Burton (9); LARKIN, Litsky \& FUller (20, 21); RAJ \& LISTON (29); SOLOWEY \& WATSON (34); WILSON \& MCCleskly (37), entre outros), em face do que os alimentos elaborados que se apresentem livres de estreptococos fecais estão, com grande probabilidade, livres também de patogênicos entéricos; além disso, a ausência de germes enterococos reflete boas condiçōes higiênico-Sanitárias do estabelecimento produtor.

$\Lambda$ par de tôdas essas consideraçōes, entretanto, deve-se assinalar que o número de bactérias fecais nos alimentos, sofre determinadas limitaçōes na dependência do produto considerado. Realmente, as manibras tecnológicas inerentes à industrialização, fazem oscilar grandemente os teores em coliformes e enterococos. E o que verificaram AlLeN \& FABBIAN $(1,2)$, ao comparar os números de $E$. coli e Str. faeralis que ocorriam $\mathrm{cm}$ alimentos de tecnologia diversa, particularmente com valores diferentes de $\mathrm{pH}$. Da mesma forma, LARKIN, LITSKY \& FULLER (21) estudaram 80 amostras de pescado congelado, comparando os resultados com os dois grupos de germes e concluindo que há sempre maior número de enterococos do que de coliformes; SOLOWEY \& WATSON (34) pesquisaram a flora bacteriana de ovos $\mathrm{em}$ pó com alto teor de umidade, constatando a presença de enterococos e ausência de coliformes; acham êsses autores que os enterococos, em condiçōes propicias, multiplicam-se no ôvo em pó, mas mesmo assim consideram que devido à falta de correlação entre a presença de $E$. coli, dos coliformes, das salmonelas e contagem global de bactérias, deve-se dar mais atenção aos enterococos como indicadores de poluição fecal ou como indicadores de falta de medidas higiênicas durante a produção. KELLY \& ANCISZ (18) encetaram estudo para testar a sobrevivência de germes entéricos em ostras c mariscos, concluindo que a $E$. coli aumenta sobremodo em número após estocagem prolongada, o que é séria desvantagem para um germe tido como indicador de poluição, pois, não seria capaz de indicar as condiçōes iniciais de contaminação; MoRris \& WEAVER (24) pesquisaram uma sćrie de amostras de água de poços usadas para a indústria alimentar, com a finalidade de avaliar a eficiência de coliformes e enterococos no julgamento do grau de poluição. 
Foram concordes ao afirmar que o número de coliformes e enterococos era, em média, idêntico na constataçāo de poluição de água recentemente coletada; em amostras de águas estocadas por 24 horas, os enterococos apresentaram-se superiores dos coliformes para a finalidade proposta.

WiLson \& MCCLeskly (37) estudaram a incidência de entero$\operatorname{cocos}, E$. coli e coliformes em ostras, correlacionando o número désses germes. Argumentam que sendo a $E$. coli tida durante muito tempo como o melhor indicador de poluição lecal, pode-se admitir que qualquer germe que habite o intestino e cujo número seja correlato ao dela, pode, identicamente, ser usado como indicador de poluição. Na verdade, êsses autores concluem que as ostras que apresentam elevado teor em coliformes, contém também elevado teor em $E$. coli e enterococos, sendo verdadeiro também o achado inverso. Esse fato justificaria, na opinião dos autores citados, o emprêgo de enterococos como indicadores de poluição.

Vantagens da utilização do indice de estreptococos fecais para laranja concentrada congelada foram assinaladas por HAH \& APplemanN (15), ao passo que Niven JR. (26), citando vårios autores, aponta as virtudes désse indice para frutas e verduras congeladas, tortas de carne congeladas, tortas congeladas de galinha e refeiçōes pré-cozidas e congeladas.

Um outro aspecto que deve ser considerado ao tratar-se da pesquisa de bactérias fecais, diz respeito a que elas $e$, muito particularmente, os enterococos, podem ser incriminados como responsaiveis por algumas toxinfecçōes alimentares (BUTTIAUX $(10,11)$; NIVEN JR. (26); Silliker \& Deibel (33)). Num trabalho sôbre o assunto, BUCHBINDER, OSLER \& STEPIIEN (8), apresentam evidêncids sôbre a implicação dêsses germes como possiveis microrganismos responsáveis por quatro epidemias de toxinfecçāo alimentar de tipo relativamente brando. Os alimentos em questĩo eram produtos lácteos ou cárneos entre os quais o leite evaporado.

Por outro lado, Moore (23), num amplo trabalho sôbre os estreptococos e as intoxicações alimentares, afirma que "a incerteza que ainda cerca a classificação dos estreptococos fecais reflete-se na informação inadequada que se encontra na literatura sôbre estreptococos e sua relação com epidemias de intoxicaçōes alimentares". Ainda nêsse mesmo sentido, Silerman, Smiley \& NiveÑ JR. (32), estudando um estreptococo que havia sido responsabilizado por toxinfecçōes alimentares contraidas pela ingestão de queijo, identificaram-no como sendo o Streptococcus faeralis, pertencente ao grupo sorológico D de Lancefield.

Niven JR. \& White (27), estudando uma coleção de 113 culturas de estreptococos, isoladas de 100 casos de endocardite bacteriana 
sub-aguda, atribuiram cinco casos ao Streptoroccus faecalis, que foi veiculado, provàvelmente, por alimentos lácteos.

Em última análise, portanto, é bastante difícil avaliar-se o grau de contaminação dos alimentos. Para os de origem animal, cuja elaboração envolve, na maioria das vêzes, manipulação diversa, estando, porisso, sujeitos a uma enorme séric de alterações de ordem física, química e biológica, é realmente difícil formar idéia exata sôbre as condiçōes higiênico-sanitárias que comandaram as variadas fases de preparação dos produtos, desde a obtenção da matériaprima até a sua manipulação, distribuição e momento de consumo.

Por outro lado, os serviços de inspeção sanitária sempre buscaram um método laboratorial que permitisse, de forma segura, aquilatar as circunstancias que dominaram durante a fabricação de determinado alimento; em última análise, um processo através do qual seja possivel ter-se reflexo fiel e rápido das condiçōes higiênicas que cercaram a preparação. O problema torna-se evidentemente sério, quando se atenta para o fato de que nem todos os alimentos mostram, de forma nítida c, sobretudo, fàcilmente avaliável, quando foram elaborados precàriamente. Determinadas incorreçōes, perpetradas durante a tecnologia de certos gêneros alimenticios, podem ficar mascaradas pelas imposições de algumas manobras concernentes à sua tecnologia. E o caso de alimentos cozidos que, embora conspurcados durante a sua fabricação, pela atuaçāo de operários inexperientes ou pela adoção de técnicas inadequadas, não apresentam alterações visiveis após o preparo, às vêzes nem mesmo mediante certos testes de laboratório, visto terem sido tratados pelo calor.

Afora a inconteste importância que representa a matéria-prima como fator de contaminação, das imperfciçōes e irregularidades cometidas durante a manipulação dos alimentos, são realmente sérias aquelas que redundam na contaminação dos produtos por excretas humanas ou de animais. A poluição fecal dos alimentos revela, também, precariedade das condições higiênico-sanitárias do estabelecimento e das pessoas que, direta ou indiretamente, tenham tido contato com os produtos. Além disso, tais excrementos podem se constituir, por vêzes, em veiculo de determinados germes, responsáveis por um número relativamente grande de doenças no homem.

Aliás, a ocorrência de microrganismos nos alimentos consumidos pelo homem, foi constatada já nos primórdios da era bacteriológica. Estendendo-se o raciocinio de CHRISTOVão (13) aos alimentos, pode-se afirmar que o risco de toxinfecçāo ligado aos produtos contaminados prende-se, em grande parte, à presença nêles de microrganismos patogênicos provenientes das fezes e, eventualmente, da urina de individuos doentes ou portadores de germes. Assim, o perigo de transmissāo de doença infecciosa através dos alimentos, está representado, principalmente, pelas doenças infecciosas intestinais. 
Ora, o problema em saber se determinado produto alimentício pode ser dado a consumo sem riscos para o consumidor, é parcialmente resolvido ao se constatar se êle foi ou não poluido por fezes o que, bacteriológicamente, é conseguido procurando-se nêle bactérias fecais. Destas, as patogênicas são, reconhecidamente, de dificil detecçāo e isolamento, porquanto crescem dificilmente em meios de cultura comuns ou, então, nāo conseguem competir com outros organismos em meios artificiais, em razāo do que o seu desenvolvimento é bastante demorado.

Tais dificuldades concernentes à pesquisa dos germes patogênicos, levaram os estudiosos a procurarem um germe ou, então, um grupo de germes que se associassem normalmente aos patogênicos intestinais e fôssem de mais fácil isolamento; êsses germes, sendo menos exigentes quanto aos fatôres de crescimento, de mais fàcil identificação c menos perigosos em relação às possibilidades de contaminação e disseminação, poderiam funcionar como reveladores da possivel presença dos patogênicos em alimentos.

A luz destas consideraçōes, o presente estudo foi conduzido para determinar a viabilidade de coliformes e enterococos $\mathrm{em}$ produtos lácteos de diferente tecnologia, o que, parece, proporcionará alguns subsidios par'a se açuilatar a adeçuação de cada um como microrganismo satisfatório na avaliação da contaminaçāo fecal dos alimentos. Com êsse propósito procurou-se comparar a incidência dêsses germes em manteiga sem sàl, em queijo "Minas" fresco e duro, em queijo Prato, em leite pastcurizado lipo "C", em queijo tipo "Muzzarella", em leite em pó integral e desnatado e em queijo tipo "Parmezão". Observou-se, portanto, a resistência dêsses germes em face às manobras tecnológicas perpetradas durante a elaboração dos produtos referidos.

\section{MATERIAL E: ME:TODOS}

Amostras de leite, leite em pó, manteiga e (jueijos, num total de 214, coletadas pela Inspetoria Regional do Serviço de Inspeção de Produtos Agro-Pecuários e Materiais Agricolas (SIPAMA), em alguns estabelecimentos sob sua jurisdição, localizados no Estado de São Paulo, constituiram o material utilizado no presente estudo. Foram analisadas 39 amostras de manteiga sem sal; 26 de queijo "Minas" Iresco; 18 de queijo "Minas" duro; 19 de queijo Prato; 17 de leite pasteurizado tipo "C"; 19 de queijo tipo "Muzzarella"; 32 de leite $\mathrm{cm}$ pó integral; 23 de leite $\mathrm{cm}$ pó desnatado e 21 de queijo tipo "Parmezão".

Os meios de cultura seletivos empregados foram o caldo bile verde brilhante a 2"; (Difco n. ${ }^{\circ} 0007-01$ ) e o agar Levine EMB (Difco n." 0005-01), para a pesquisa de coliformes, enquanto que para a detecção dos enterococos foram utilizados os meios preconizados por 
Litsky, Mallmann \& Fifield (22), modificados por RaJ, Wiebe \& LISTON (30) e o agar com tetrazólio e acetato de tálio (BARNES (4)).

O meio de cultura preconizado por LITSKY, MALLAMNN \& FIFIEL (22), compreende duas fases: uma presuntiva, cujo substrato básico é a azida sódica $\left(\mathrm{NaN}^{3}\right)$ e a dextrose $(\mathrm{AD})$ e uma confirmativa, onde aparecem, além da azida sódica e da dextrose, o corante etil violeta (EVA). A composição, em gramas por cento, das duas fases ć a seguinte: FASE PRESLNTIVA (AD) : triptose, 2,0; dextrose, 1,$5 ; \mathrm{NaC} 1,0,5 ; \mathrm{K}_{2} \mathrm{HPO}_{1}, 0,27 ; \mathrm{KH}_{2} \mathrm{PO}_{1}, 0,27 ; \mathrm{NaN}_{3}, 0,02$. FASE CONFIRMATIVA (EVA): triptose, 2,0; dextrose, 1,5; NaC1, 0,5; $\mathrm{K}_{2} \mathrm{HPO}_{1}, 0,27 ; \mathrm{KH}_{2} \mathrm{PO}_{1}, 0,27 ; \mathrm{NaN}_{3,}, 0,04$.

Fistes meios, entre muitos utilizados no isolamento e enumeração dos enterococos, foram os preferidos tendo em vista a simplicidade de técnica e a especificidade para microrganismos do grupo sorológico D de Lanceficld, repuisitos comprovados pelos autores em um amplo estudo sôbre a eficiencia de meios seletivos para os germes em questảo. Inicialmentc usado como teste para enterococos em amostras de águas de rios contaminados por esgôto, o meio de LITSKY, MaLl.MaNN \& Firikil) (22), era constituido originalmente pela primeira fase; observou-se, entretanto, que as bactérias Gram negativas eram inibidas c que alguns formadores de esporos como o Bucillus substilis conseguiam crescer. Essa razão levou os autores a adicionarem um outro agente inibidor, necessário para remover as bactérias Gram positivas que nāo fôssem enterococos. Nessas condições, um corante bacteriostático, inibidor de bactérias Gram positivas, o etil violeta, foi utilizado. Passou-se, então, a usar o meio com duas fases distintas, a presuntiva, empregando a azida sódica e a dextrose, e a confirmativa, o etil violeta, a azida sódica e a dextrose, como substâncias fundamentais.

Os estudos de Litsky, Mall.MinNn \& Fifield (22) justificam a aplicaçāo dos meios citados para a pesquisa de enterococos pois, como concluiram esses autores, os resultados fornecidos são particularmente interessantes quanto ao fato da especificidade dos meios para aquêles germes, uma vez que em tôdas as provas realizadas ficou patente a inibiçăo das bactérias Gram negativas e Gram positivas (que não enterococos).

Tendo em vista os ótimos resultados obtidos ùltimamente com os meios descritos (BARNeS (4); LARKIN, LiTSKY \& FUl.Ler (20, 21); LitSky, Malmann \& Firield (22), resolveu-se usá-los na presente pesquisa, mas, com a modificação sugerida por RAJ, WIEBE \& LISTON (30), os quais, introduzindo o azul de bromo timol (na concentraçāo de $0,003 \%$ ) à primeira fase do meio, conseguiram maior especificidade quando o mesmo era usado para a detecção de enterococos em alimentos. Além disso, para maior segurança no teste 
confirmativo, procurou-se um meio sólido que pudesse referendar os resultados obtidos na segunda fase: o agar com tetrazólio e acetato de tálio, recomendado por BARNes (4).

Relativamente à técnica adotada, cujo esfjuema apresenta-se na Figura I, variou de conformidade com o produto analisado, segundo os métodos preconizados pelo "Standard Methods for the Examination of Dairy Products" (3) para a pesçuisa bacteriológica do leite, do leite em pó, da manteiga e dos queijos. De forma geral, recebida a amostra no laboratório, procedia-se a diluições decimais do material, usando sempre a soluçāo de Ringer como líquido diluidor. À seguir, alị́uotas idênticas de cada diluição $(1 \mathrm{ml})$ eram semeadas, concomitantemente, nos meios empregados como presuntivos. Após incubaçāo por 48 horas a $35 \mathrm{C}$, cada tubo positivo de CBVB era confirmado, semeando-se $0,1 \mathrm{ml}$ de seu conteúdo no meio sólido de agar Levine EMB (ALEMB). Decorridas 24 horas de incubação a $35^{\circ} \mathrm{C}$, caso as colônias desenvolvidas no ALEMB mostravam-se típicas para coliformes, então computava-se como definitivo o resultado constatado nos tubos de CBVB, resultado esse interpretado numèricamente através do número mais provável (3). Na eventualidade de que algum tubo positivo de CBVB nāo fornecesse colônicas típicas, era cle desprezado c não considerado para a interpretação numérica.

Para os enterococos foram procedidas duas confirmações. Das diluiçôes eram semeados volumes idênticos $(1 \mathrm{ml}) \mathrm{em}$ séries de tubos com o meio $\mathrm{AD}$. Após incubação por 48 horas a $37^{\circ} \mathrm{C}$, os lubos positivos cram confirmados em tubos com o meio EVA. Passadas outras 48 hor'as de incubação a $37^{\circ} \mathrm{C}$, os tubos EVA positivos eram reconfirmados no meio sólido de agar com tetrazólio e acetato de tálio (ATAT), num volume de $0,1 \mathrm{ml}$ de cada tubo. Caso noste último meio se desenvolvessem colônias tipicas, ou melhor, se todos os tubos positivos na segunda fase do meio de LITSKY, MalmanN \& Fifield (22), modificado fornecessem, pela semeadura no meio ATAT, resultados também positivos, então consideravam-se como definitivos os resultados obtidos no meio EVA, os (quais eram computados pelo número mais provável (3).

\section{RESLITADOS}

A quantidade de germes coliformes e enterococos, determinada segundo a técnica descrita no capítulo de Material e métodos, pode ser apreciada nas Tabelas de I a IX, que mostram o tcor dêsses microrganismos para cada um dos produtos analisados.

Os Quadros de Associação, que aparecem após cada Tabela resumem a análise estatística dos resultados, determinada à custa do aspecto qualitativo. Assim, para a Tabela I, onde são apresentados os teores em coliformes e enterococos encontrados em 39 
amostras de manteiga sem sal, o Quadro de Associação correspondente mostra que existem 26 resultados concordantes (relativamente ao sinal positivo ou negativo), entre as provas para a detecção de coliformes e para a detecção de enterococos. Dos 13 resultados discordantes, 11 foram negativos para germes coliformes e positivos para germes enterococos, enquanto que 2 foram negativos para enterococos e positivos para coliformes. Tais resultados, interpretados pelo teste da binomial, mostraram maior positividade para a presença de enterococos em relação à de coliformes, com significância ao nivel de 5\%; (teste monocaudal).

Da mesma forma, a Tabela II apresenta os teores em coliformes c enterococos detectados em 26 amostras de queijo "Minas" fresco. O Quadro de Associação correspondente demonstra que existem 20 resultados concordantes entre as duas provas; dos 6 discordantes, 5 foram negativos para germes coliformes e positivos para germes enterococos, e apenas 1 foi negativo para en1erococo c positivo para coliforme. Fsses resultados, interpretados pelo teste da binomial, mostraram maior positividade para a presença de enterococos $\mathrm{cm}$ relação à de coliformes, porém não houve significância ao nivel de $5 ;$, (teste monocaudal).

Relativamente ao queijo "Minas" duro, a Tabela III reúne os resultados obtidos com 18 amostras dêsse produto. O Quadro de Associaçāo correspondente mostra 9 resultados concordantes; dos 9 discordantes, 8 foram negativos para germes coliformes e positivos para germes enterococos e 1 foi negativo para enterococos e positivo para coliformes. Calculados pelo teste da binomial, mostraram maior posilividade para a presença de enterococos em relação à de coliformes, com significância ao nivel de 5\% (teste monocaudal).

A Tabela 4 resume os resultados obtidos com 19 amostras de queijo Prato. O Quadro de Associação correspondente revelou 13 resultados concordantes; dos 6 discordantes, 5 foram negativos para germes do grupo coliforme e positivo para germes do grupo enterococo, enquanto que apenas 1 foi negativo para germes do grupo enterococo e positivo para germes do grupo coliforme. A interpretaçāo estatistica mostrou, pelo teste da binomial, maior positividade para a presença de enterococos em relação à de coliformes, com nāo significância ao nível de 5\%; (teste monocaudal).

Já, a pesquisa dos dois grupos de germes em leite pasteurizado tipo "C", aparece na Tabela $V$, que mostra os resultados com 17 amostras dêsse produto. O Quadro de Associação opereceu 12 resultados concordantes; dos resultados discordantes, 5 foram negativos para germes coliformes e positivos para enterococos, não havendo nenhum resultado negativo para enterococos e positivo para coliformes. Consequientemente, a interpretação estatistica mostrou po- 
sitividade exclusiva para a presença de enterococos em relação à de coliformes, com significância ao nivel de $5 \%$ / (teste monocaudal).

A comparação da incidência de germes coliformes e enterococos foi executada ainda, em 19 amostras de queijo tipo "Muzzarella", como se pode ver ao examinar-se a Tabela VI. Do estudo do Quadro de Associação correspondente, depreende-se que foram concordantes 7 resultados e discordantes 12 , dos quais 11 foram negativos para germes coliformes e positivos para enterococos e, 1 apenas, negativo para enterococos e positivo para coliformes. Aplicando o teste da binomial, demonstrou-se a positividade maior para a presença de enterococos $\mathrm{cm}$ relação à de coliformes, com significância ao nivel de $5 \%$ (teste monocaudal).

Por outro lado, o teor em coliformes e enterococos em leite em pó integral foi avaliado à custa de 32 amostras do produto, estando os resultados coligidos na Tabela VII. O Quadro de Associação correspondente indica 2 resultados concordantes e 30 discordantes, dos quais a totalidade ofereceu positividade para germes enterococos e negatividade para germes coliformes, evidenciando, pelo teste binomial, positividade exclusiva daquêles em relação à êstes. Houve, portanto, significância dos resultados, ao nível convencionado de $5 \%$ (1este monocaudal).

Com referência ao leite em pó desnatado, foram realizadas 23 análises com êsse produto, estando os resultados esquematizados na Tabela VIII. O Quadro de Associação não revelou nenhum resultado concordante; dos discordantes, 23 foram negativos para coliformes e positivos para enterococos. Tais resultados, interpretados estatisticamente pelo teste binomial, fazem concluir por uma positividade maior para a presença de enterococos em relação à de coliformes, com significância ao nivel de $5 \%$ (1este monocaudal).

Finalmente, a Tabela IX apresenta os teores em coliformes e enterococos encontrados em 21 amostras de queijo tipo "Parmezão". O Quadro de Associação mostra que existem 3 resultados concordantes e 18 discordantes, dos quais todos êles foram negativos para coliformes e positivos para enterococos. Há, portanto, definição de uma positividade maior para a presença de enterococos em relação à de coliformes, como demonstrou-se pelo teste da binomial, com franca significância ao nivel de $5 \%$ (teste monocaudal).

Quanto ao aspecto quantitativo dos resultados, considerando-se os casos de concordância positiva (positividade tanto para coliformes quanto para enterococos) e analisando-se estatisticamente a diferença entre os teores de germes dos dois grupos, através o teste $t$ aplicado à variável transformada (transformaçāo logaritmica), encontrou-se uma supremacia numérica de enterococos em relação a coliformes, significante ao nivel de $5 \%$ (teste monocaudal), para 
a manteiga sem sal, para os queijos "Minas" fresco e duro, para o queijo Prato, para o queijo tipo "Muzzarella" e para o queijo tipo "Parmezão" (Tabelas I, II, III, IV, V, VI, VII, VIII e IX). Quanto aos leites em pó integral e desnatado (Tabelas VII e VIII), a simples inspeção das respectivas tabelas basta para evidenciar a predominância numérica dos enterococos sôbre os coliformes.

\section{DISCUSSÃO}

O estabclecimento de padrões bacteriológicos para os alimentos de origem animal, foi, é e parece que será preocupação constante de inspetores e tecnologistas. Particularmente para o leite e produtos dêle derivados, a determinação de um índice que reflita as condiçōes higiênico-sanitárias de produção e manipulação, reveste-se da mais alta importância. Tradicionalmente utilizados para aquilatar a qualidade bacteriológica da água e do leite, a $E$. coli e o grupo coliforme, foram sendo gradativamente estendidos a outros alimentos com a mesma finalidade. Entretanto, evidencias existem segundo as quais os microrganismos usualmente empregados como indicadores de poluição fecal para a água e para o leite, são insatisfatórios quando aplicados para outros alimentos (KERELUK \& GUNDERSON (19); LARKiN, LiTSKY \& Fuller $(20,21)$; ZabAROWSKI, HUBER \& RAYMAN (38)). Esta afirmativa, segundo KELLY (cit. RAJ \& LISTON (28)), é verdadeira inclusive no caso de moluscos, para os quais os métodos de avaliação da qualidade bacteriológica através dos coliformes, têm sido usados por muitos anos. É amplamente reconhecido que a contagem de coliformes pelo número mais provável tem utilidade limitada para alguns produtos, devido a origem diversa dos microrganismos incluidos no grupo coliforme, muitos dos quais derivam de fontes não humanas, podendo-se esperar normalmente a sua presença $\mathrm{em}$ certos produtos crus ou manufaturados.

RAJ, WIEBE \& LiSTON (30) assinalam, por outro lado, a insuficiência dos coliformes quando usados para avaliar o grau de poluição fecal de produtos congelados, como é o caso do pescado, enquanto HAHN \& APPLEMANN (15) chegaram à mesma conclusão relativamente ao suco de laranja concentrado e congelado. Efetivamente, a pequena resistência désses germes às baixas temperaturas, faz com que sejam impróprios para a finalidade pesquisada, fato que levou alguns autores (KERELUK \& GUNDERSON (19); LARKIN, Litsky \& Fuller $(20,21)$; Zabarowsky, Huber \& RAYMAN (38)) a advogarem o uso dos enterococos, em substituição aos coliformes, como indicadores de contaminação fecal para produtos congelados.

Parecem, pois, ủteis os estudos que esclareçam a possibilidade do índice enterococo ser utilizado para outros alimentos, mormente para aquêles que sofrem processos de industrialização e conserva- 
ção mediante a aplicaçāo do frio, calor e desidratação. Os resultados obtidos no presente trabalho talve\% contribuirão para futuras argumentaçōes nesse setor tão discutido da bacteriologia alimentar. Assim, um ponto que acreditamos ter ficado patente, diz respeito à possibilidade dos coliformes serem destruidos durante algumas fases de elaboração tecnológica dos produtos, caracterizadas pela aplicação de altas temperaturas, de desidrataçāo, de longos periodos de maturação c armazenamento.

Portanto, na dependência das diversas manobras que envolvem a tecnologia de alguns produtos, os coliformes podem ser destruídos ou ter o seu número diminuido, e a sua ausência em provas bacteriológicas posteriores poderá levar a errôneas interpretações acĉrca das condiçōes sanitárias que caracterizaram as fases de elaboração do produto. Este fato parece bem demonstrado no presente estudo, onde procuramos analisar produtos de tecnologia variada, o que possibilitou uma comparação da incidência de coliformes e enterococos.

Veja-se, por exemplo, os resultados obtidos com produtos cuja tecnologia compreende, em uma de suas fases, o emprêgo de temperaturas altas, como o queijo Prato (Tabela IV), o leite pasteurizado tipo "C" (Tabela V) c o queijo tipo "Muzzarella" (Tabela VI). Houve patente predominância numérica dos enterococos sôbre os coliformes, estatisticamente demonstrada através o teste $t$ aplicado à variável transformada (transformação logarítmica), com significância ao nivel de 5'; (tese monocaudal). Em contraposição, a positividade para enterococos e a negatividade para coliformes mostrou resultados não significantes ao nivel de 5 '; para o queijo "Minas" fresco (Tabela II e respectivo Quadro de Associação), embora o teor de germes enterococos superasse, numericamente, o de coliformes quando havia positividade para os dois grupos (teste $t$ aplicado à variável transformada). Ora, nada mais justo de esperar-se tais resultados para um produto que, na maioria das vêzes, é preparado com leite não pasteurizado, nāo sofre pràticamente qualquer processo de maturação ou outra manobra tecnológica e que, porisso, apresenta idênticas condições de desenvolvimento tanto para coliformes quanto para enterococos.

Parece demonstrada, portanto, nos produtos citados, a maior resistência dos enterococos sôbre os coliformes relativamente às temperaturas elevadas. A propósito, segundo INGRAM \& BARNES (16), a resistència dos estreptococos fecais ao calor é aparentemente governada por fatōes como o tipo do meio, o $\mathrm{pH}$, a idade do "inoculum". JENSEN (17) afirma que essa resistência ć aumentada quando óleos ou gorduras são usados como meio de suspensāo; assim, os microrganismos que são destruidos em leite, a 67,7 " $\mathrm{C} \mathrm{cm}$ 30 minutos, quando suspensos em manteiga derretida somente foram destruidos em 50 minutos a $115^{\circ} \mathrm{C}$ e em 20 minutos a $120^{\circ} \mathrm{C}$. 
Whie (36) mostrou, por outro lado, que o tempo de redução decimal do número dêsses germes, a $60^{\circ} \mathrm{C}$, é de 5 a 10 vêzes maior $\mathrm{em}$ leite do que em solução de Ringer, o que demonstra a influência do meio sôbre a sobrevivência dos enterococos.

Tendo presentes as conclusões de INGRAM \& BARNes (16), JENSEN (17) e WHITE (36), considerem-se os resultados obtidos com a análise da manteiga sem sal, produto que sofre a interferência de inúmeros fa1ôres, dos quais os mais importantes sāo os que induzem as gorduras à degradação, hidroliticamente (na primeira fase), com o aparecimento de ácidos graxos livres e oxidativamente (na segunda fase), originando aldeídos e cetonas. Dentre os fatôres citados, a luz e a umidade desempenham papel preponderante, acarretando profundas modificaçōes na composição química do produto, que afetam a sobrevivência da flora microbiana eventualmente existente, destruindo alguns microrganismos, permitindo o desenvolvimento de outros, procedendo enfim, a uma verdadeira seleção. Tais condiçōes parecem restringir a sobrevivência da flora coliforme, não interferindo (ou, pelo menos, interferindo $\mathrm{em}$ menos grau) sôbre os estreptococos fecais. Nossos resultados parecem referendar os de AlıLEN \& FAIBIAN (2), no concernente à maior resistência dos enterococos às modificações do meio, particularmente no que se relaciona com $\mathrm{pH}$ baixo e presença de ácidos graxos livres; efetivamente, o Quadro n." 1 é ilustrativo ao comprovar essa maior resistência dos enterococos, estatisticamente significante tanto do ponto de vista qualitativo quanto quantitativo. De qualquer modo, parece haver necessidade de investigações futuras sôbre êste problema, que venham responder definitivamente acêrca da resistência désses germes aos mais variados ambientes.

Relativamente aos produtos cuja tecnologia compreende longos periodos de "cura" ou maturação, devem ser ressaltados os resultados obtidos no trabalho $\mathrm{cm}$ pauta. Apresentaram-se, ainda desta vez, maiores vantagens para os enterococos, traduzindo a maior resistência dêsses germes à essa circunstância. Assim, a análise das 21 amostras de queijo 1ipo "Parmezão" (Tabela IX) revelou significativa positividade para enterococos $\mathrm{em}$ relação a coliformes, além de uma supremacia numérica dos primeiros em relação aos segundos quando havia positividade para os dois grupos, fato estatisticamente comprovado. O mesmo ocorreu com o queijo "Minas" duro, o qual sofre também longo período de cura. A propósito, convém comparar os resultados obtidos com os queijos "Minas" duro (Tabcla III) e tipo "Parmezão" (Tabela IX) com aquêles fornecidos pelo queijo "Minas" fresco (TabelaII); tal comparação oferece argumentos para concluir sôbre a maior resistência dos enterococos nos produtos lácteos armazenados por longos periodos. Efetivamente, é altamente significante o fato de que no queijo "Minas" fresco houve positividade tanto para enterococos quanto para 
coliformes, enquanto no tipo "Parmezão" e "Minas" duro constatou-se franca positividade para enterococos ou, ao menos, supremacia numérica indiscutivel dêstes germes sôbre aquêles. Ora, tais resultados são justificados, tendo-se em conta as profundas transformações que se instalam na massa dos produtos "curados", iniciando-se com a acidificação oriunda da formação de ácido lático, a cual já é suficiente para inibir grande número de espécies bacterianas, entre as quais os representantes do grupo coliforme.

Finalmente, devem merecer destaque especial os resultados obtidos com a análise dos leites em pó integral c desnatado, para os quais verificou-se predominio total dos enterococos, com negatividade completa dos coliformes. Estes achados confirmam ainda uma vez a resistencia dos enterococos às temperatur'as clevadas $\mathrm{c}$ à dessecação, motivo pelo qual deveriam merecer mais atenção no relativo a serem utilizados, em substituição aos coliformes, como microrganismos testes de poluição fecal para os produtos citados. Realmente, os nossos resultados referendam a opinião de Brown \& GribBoxs (7) e Solowey \& Watson (34), muito embora êstes autores tenham trabalhado com ovos em pó. Entretanto, a tecnologia de elaboração deste produto aproxima-se bastante, no que se refere às temperaturas e às condições de desidratação, dacuela utilizada para leites em pó. Realmente, em um ou outro produto, a matéria-prima sofre a ação de temperaturas bastante clevadas, quer na fase de pasteurização do leite $(80 \mathrm{C})$, (juer no "spray", onde o impacto com o ar aquecido faz o leite atingir temperaturas que oscilam ao redor de $100^{\circ C}$. Segundo BtTTIAt: (12), traduzindo a opinião de muitos autores, essa resistência dos enterococos deveria ser encarada como uma razão para usá-los, em substituição aos coliformes ou em complementação a èles, como indicadores de poluição fecal.

Resta-nos comentar sôbre a possibilidade de os enterococos serem, acidentalmente, usados como fermentos láticos selecionados para a fabricação da manteiga $e$ dos queijos. Fste ć um fato que deve ser argumentado, pois a utilizaçāo de "starters" no fabrico dêsses produtos, poderia trazer alguma confusão quando os estreptococos fecais fôssem usados como indicadores de poluição. É sabido que tais "starters" são representados principalmente pelo Streptococcus lactis e pelo Streptococcus cremoris, germes não pertencentes ao grupo enterococo e propositalmente adicionadas à massa para fermentá-la. Bioquimicamente, os estreptococos láticos aproximam-se bastante dos estreptococos fecais e a presença dêstes últimos nos produtos poderia não traduzir realmente poluição fecal, mas, simplesmente, a adição acidental de estreptococos fecais (associados com os "starters"), o que levaria a uma falsa interpretação dos resultados, mesmo porque os produtos lácteos de modo geral representam um ótimo ambiente para a maioria dos 
estreptococos. A estas consideraçōes pode-se replicar ùnicamente lembrando que só resta confiar nos meios de cultura scletivos os quais, funcionando a contento, seriam os únicos a resolver, pelo menos no estado atual dos conhecimentos, o problema em questāo.

\section{SLMMARY}

Researching the representatives of the enterococci and coliform groups in milk and dairy products, in a total of 214 samples, and interpreting the results by means of the MPN, it was possible to determine the viability of these bacteria in dairy foods of a varied technology (saltless butter, hard and soft "Minas" cheese, "muzzarella" and "parmezão" cheese, "C" type pasteurized milk, whole and skimmed powdered milk). It was evidenced that the higher or lower occurrence of microorganisms in each group is conditioned to the chemical composition and to the technological variations inherent to the preparation of each type of product.

Thus, there was a numerical preponderance, statistically evidenced, of enterococci over coliforms in saltless butter, hard and soft "Minas" cheese, "C" type pasteurized milk, whole and skimmed powdered milk, and in the "muzzarella" and "parmezão" types of cheese. On the other hand, the chances of finding positive results for enterococei and negative for coliform are greater than the inverse in the case of saltless butter, hard "Minas" cheese and the "muzzarella" and "parmezão" types, and in the case of the "C" type pasteurized milk, and in the whole and skimmed powdered. There was an identical probability for the fresh "Minas" and Prato types of cheese.

Finally, the investigation concerning the prevalence of one or the other group in the foods referred to, seems to contribute to future considerations about adequacy as indicators of fecal poluition.

\section{RIFHERENCIAS RIBILIOGRAFICAS}

1. ALLFN, C. II. FARIAN, F. W. - Comparison of Escherichine roii and Streptororeus fueculis as a test organisms to determine the sanitary quality of food. Part I. J. Milk Food Ternol., $1 \tau(7): 204-218,1954$.

2. ALI.FN, C. H.; FAIBIAN, F. W. - Comparison of Escherichiu roli and Streptoroceus fueculis as a test organisms to determine the sanitary quality of food. Part II. J. Milk Food Terhnol., $I$ r(8):237-242, 1954.

3. AMIRICAN PUIBLIC IIEAL:TII ASSOCIATION - Standard Methods for the Fxamination of Dairy Products. 10"1, New York, American Health Association, $195 \overline{3}$.

4. BARNFS, F. M. - Differential and sclective media for the faceal streptococci. J. Sci. Food Agric., 10(12):656-662, 1959. 
5. BRASIL, MINIS'TFRIO DA AGRICLLTURA - Regulamento da Inspeção Industrial e Sanitária de Produtos de Origem Animal. Decrotos Federais n."s 30.691, do 29-3-52 c 1.255, de 25-6-62, p. 40-41, 155, 1953.

6. BREFi, R. S.; NORTON, J. F. - Nomenclature of the colon group. Amer. J. publ. Hlth., 27(6):560-563, 1927.

7. BROWN, H. J.; GIBBONS, N. F. - Fintrococei as an index of fecal contamination in egg products. Conedium $J$. Les., $2 \times(\overline{5}): 107-117,1950$.

8. IBUCHBINDFR, I.; OSLER, A. G.; STFHFliN, G. I. - Studies in onterococcal food poisoning. I. The isolation of enterococei from implicated in several outbreaks of food poisoning. Publ. H/th. Rep., G.3(4): $109-118,1948$.

9. BUIRTON, M. O. - Comparison of coliform and enterococcus organisms as indices of pollution in frozen foods. F'ood Res., /4(5):434-438, 1949.

10. BUTTIAUX, R. - Sur quelgues faits noureaux concerrant les toxi-infections alimentaires. Rel: méd. Liege, //:521-533, 1956.

11. BLTTIACX, R. - Les stroptocoques fócaux dans les eaux d'alimentation. Recherce. İspéces rencontróes. Signification. Ann. Inst. Pusteur, 95) (2):142-148, 1958.

12. BUT'IALX, R. - The value of the association Escherichice Group D streptococei in the diagnosis of contamination in foods. $J$. upplied Buct., $22: 153-158,1959$.

13. CHRIS'TOVÃO, D. A. - Exame e contrôle bacteriológicos da água, in "Operação e manutençāo de estacõos de tratamento de água, São Paulo, 1965". São Paulo, FHSP/OPAS, 1965, p. 125-198.

14. FOOD AND AGRICLLTLRE: ORGANIZATION -- Milk Hygiene, Geneva, World Health - Organization, 1962 p. 308-310.

15. HAHN, S. S.; APLFMAN, M. D. - Microbiology of frozen orange concentrate. I. Survival of enteric organisms in frozen orange concentrate. Food Terhnol, (i(4):156-158, 1952.

16. INGRAM, M.; BARNi:S, $\because$ - Streptococei in pastourized cannod hams. Am. Inst. Pusteur Lille, テ:101-114, 1955.

17. JIENSEN, I.. I3. - Microbiology of meats. 3rd ed.. Illinois Garrard Press, 1954.

18. KF.LLY, C. B.: ARCISZ, W. - Survival of enteric organisms in Shell fish Public. Health Rept's, 69(2):1205-1210, 1954.

19. KFRELUK, K.; GUNDERSON, M. F. - Studies in the bacteriological quality of frozen meat pies. I. Bacteriological survey of some commercially frozen meat pies. Appl. Mirrobiol., 千:320-323, 1959.

20. LARKIN, E. P.; IITSKY, W.; FULLER, J. F. - Fecal streptococci in frozen foods. I. A bacteriological survey of some commercially frozen foods. Appl. Microbiol., 3(2):98-101, 1955.

21. I,ARKIN, E. P.; LITSKY, W.; FULLER, J. F. - Incidence of fecal streptococci and coliform bactoria in frozon fish products. Amer. $J$. publ. Hlth., 46(4):464-468, 1956. 
22. LITSKY, W.; MALLMAN, W. L.; FIFIFILD, C. W. - A new medium for the detection of enterococci in water. Amer. J. publ. Hith, 43(7): $873-879,1953$.

23. MORRE, M. - Streptococci and food poisoning. J. uppl. Buct., 18(3): $606-618,1955$

24. MORRIS, W.; WFAVFIR, R. H. - Streptococci as indices of pollution in well-waters. Appl. Microbiol, 2(5):282-254, 1954.

25. MOSSFiL, D. A. A.; VAN DIHPIN, H. M. J.; BRLIN, A. S. - The enumeration of faccal streptococci in foods, using packer's crystal violet sodium azide blood agar. J. uppl. Buct., 20(2):265-272- 1957.

26. NIVEN, JR., C. F. - Microhial Indexes of food quality: fecal streptococci. In Shonetz, I. W.; Slanct\%, I. W.; Chicheste., C. O.; Gaufin, A. R. \& Ordal, Z. J. -Microbiological quality of foods. New York, Academic Press, 1963.

27. NIVT:N JR., C. F.e WIIITH, J. C. - A study of enterococci associated with subacule bactorial endocarditis. J. Bact., $5 /(6): 790,1946$.

28. RAJ, H.; LISTON, J. - Detection and enumeration of fecal indicator organisms in frozen sea foods. I. Escherichie coli. $\Lambda \mathrm{ppl}$. Microbiol, y(2):171-174, 1961.

29. RAJ, H.; LISTON, J. - Survival of bacteria of public health significance in frozen sea foods. Food Terh., 15(10):429-434, 1961.

30. RAJ, II.; WILBEF, W. J.; IISTON, J. - Detection and enumeration of fecal indicator organisms in frozen sea foods. II. Enterococci. $A p p l$. Microbiol., 9(4):295-303, 1961.

31. SIFRMAN; J. M. - The streptococci. Bur Rev, $\ell(1): 3-97,1937$.

32. SIHRMAN, J. M.; S.MILFY, K. L.; NIVEN JR., C. F. -- The identity of a streptococcus associatcd with food poisoning from chees: $J$. Duiry Sri., 26(4):321-323, 1943

33. SILIJKFIR, J. H.; DFIBI:L, R. II. - On the association of enterococci with food poisoning. Burt. Pior. 48, 1960.

34. SOLOWFY, M.; WATSON, A. J. - The presence of enterococci in spray dried whole egg powder. Food Res., /6(3):187-191, 1951.

35. L. S. DEPARTAMFNT OF III'AI,TII, EDLCATION, and Welfare. Public Health Service. Milk Ordinance and Code. p. 37, 47, 40, 50, 184; 1953.

36. WHITE, H. R. - The heat disinfection of Streptococcus faccalis and Streptococcus lactis. Proc. Soc. (1ppl. Buct., 15:8,1952.

37. WILSON, 'J'. H.; McCLF'SKI,Y, C. S. - Indices of pollution in nysters. fiood Res., lif(4):313-319, 1951.

38. ZABAROWSKI, II.; HLBER, D. A.; RAYMAN, M. M. - Evaluation of microbiological methods used for the examination of precooked frozen fonds. Applied Microbiol,, (;:91104, 1958. 
Fig. 1 - Sistemática da técnica adotada para a pesquisa e cómputo de germes dos grupos coliforme e enterococo incidentes em leite e produtos de lacticinios.

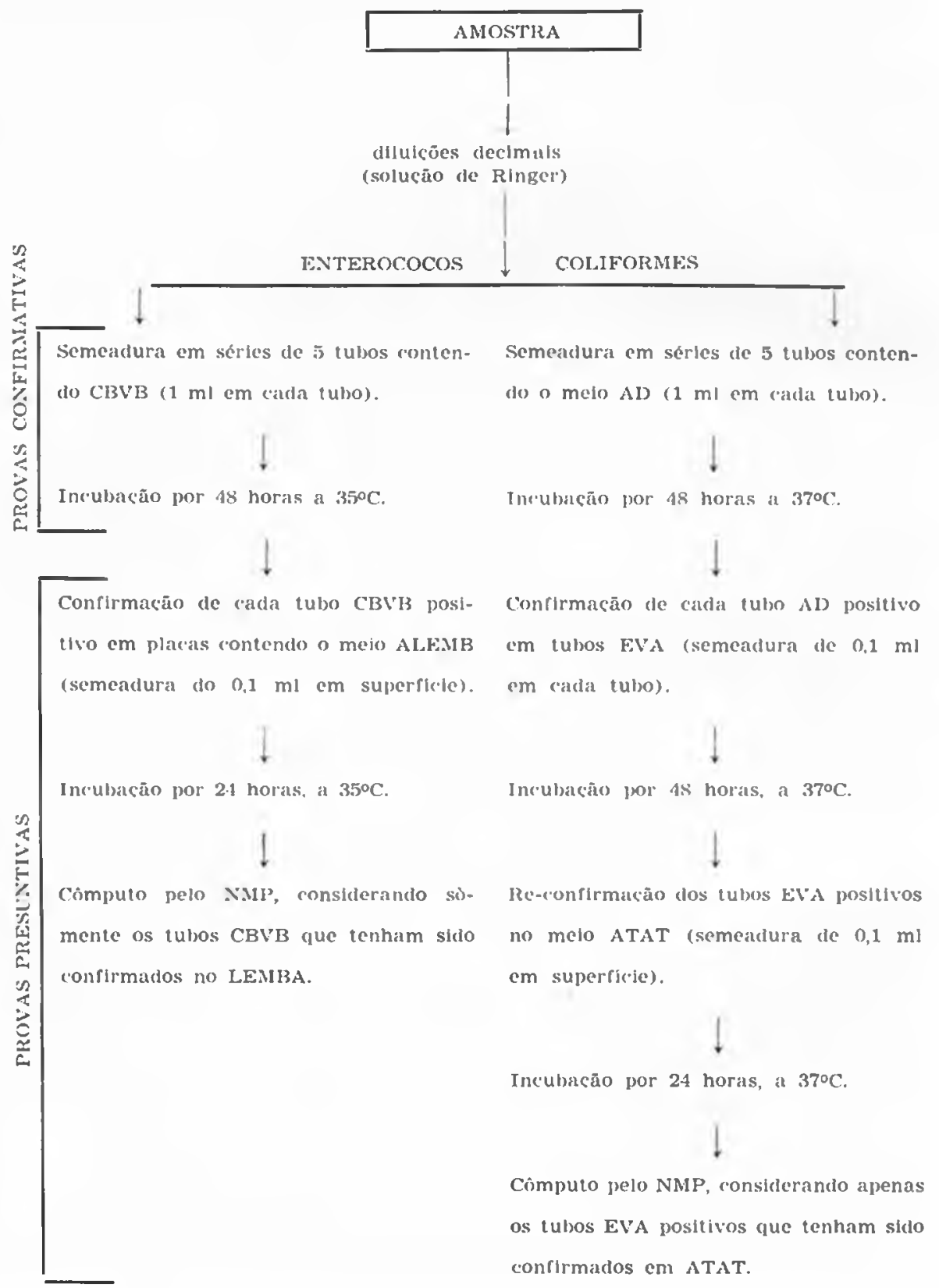


TABELA I - "Teor em coliformes e enterococos em MANTEIGA SEM SAL.

(NMP/g).

\begin{tabular}{|c|c|c|}
\hline Amostra & Coliformes & Enterococos \\
\hline 1 & 13.000 & 47.000 \\
\hline 2 & 9.5000 & 42.800 \\
\hline 3 & 2.400 & negativo \\
\hline 4 & 240.000 .000 & 600.000 .0000 \\
\hline 5 & negativo & 1.500 .000 \\
\hline 6 & negativo & $12 .(000.000$ \\
\hline 7 & 700.000 & 5.400 .000 \\
\hline 8 & 22.000 & 210.000 \\
\hline 9 & negativo & 4.900 \\
\hline 10 & 15.000 & 2.300 .000 \\
\hline 11 & negativo & negativo \\
\hline 12 & 20.000 & 570.000 \\
\hline 13 & negativo & 720.000 \\
\hline 14 & negativo & 15.000 \\
\hline 15 & negativo & negativo \\
\hline 16 & negativo & 9.200 .000 \\
\hline 17 & 2.400 .0001 & 9.200 .000 \\
\hline 18 & 12.000 .000 & 110.000 .000 \\
\hline 19 & 16.000 .000 & 24.000 .000 \\
\hline 20) & $9.200 .000)$ & 23.010 .000 \\
\hline 21 & $35.0000 .0000)$ & 240.000 .000 \\
\hline 22 & 24.000 .000 & 3.500.000 \\
\hline 23 & 1.000 .000 & $17.000 .000)$ \\
\hline $2 \cdot 1$ & $2 \cdot 10.00(0) .000$ & 725.000 .0100 \\
\hline 25 & 1.800 .000 & 2.250 .000 \\
\hline 26 & 92.000 .000 & negativo \\
\hline 27 & 54.000 .000 & 192.000 .000 \\
\hline 28 & 230.000 & 19.500 .000 \\
\hline 29 & negativo & 54.000 .000 \\
\hline 30 & 2.000 .000 & 70.000 \\
\hline 31 & 130.000 & 350.000 \\
\hline 32 & negntivo & 110.000 \\
\hline 33 & 1.100 .000 & 20.000 .000 \\
\hline 34 & 1.300 .000 & 200.000 \\
\hline 35 & negativo & negativo \\
\hline 36 & negativo & $3.500 .(6) 0$ \\
\hline 37 & negativo & negativo \\
\hline $3 x$ & negativo & 2.300 \\
\hline 39 & negativo & 450 \\
\hline
\end{tabular}

Quadro de assoriacão referente à Tabela I

\begin{tabular}{|r|r|r|c|}
\hline Coliformes & - & + & Total \\
+ & -11 & 22 & 33 \\
\hline- & 4 & 2 & 6 \\
\hline Total & 15 & 24 & 39 \\
\hline
\end{tabular}

Resultados significantes ao nivel de $5 \%$ (teste monocaudal). 
TABEI.A II - Teor em roliformes e enterococos em QUEIJO "MINAS" FRESCO. (NMP/g)).

\begin{tabular}{|c|c|c|}
\hline Amostra & Colliformes & Enterococos \\
\hline 1 & 170.000 & 240.000 .000 \\
\hline 2 & 79.000 & $170.000)$ \\
\hline 3 & 780.000 & 23.000 .000 \\
\hline 4 & 20.000 & 330.000 \\
\hline 5 & 2.400 .000 & 24.000 .000 \\
\hline 6 & 27.000 .000 & 57.000 .000 \\
\hline 7 & negatlvo & 700.000 \\
\hline 8 & 240.000 .000 & 8.600 .000 .000 \\
\hline 9 & negativo & $370.0(x)$ \\
\hline 10 & 240.000 .000 & 680.000 \\
\hline 11 & 50.000 .000 & 78.000 .000 \\
\hline 12 & 2.300 .0000 & 125.000 .000 \\
\hline 13 & negativo & $25.000 .0(1)$ \\
\hline 14 & $3.500 .0(k)$ & 8.000 .000 \\
\hline 15 & 3.500 .000 & $4.000 .000)$ \\
\hline 16 & 490.000 & 61.000 .000 \\
\hline 17 & 170.000 & 340.000 \\
\hline 18 & negativo & -4.000 .000 \\
\hline 19 & 2.850 .000 & negativo \\
\hline 20) & 20.000 & 330.000 \\
\hline 21 & negativo & 560.000 \\
\hline 22 & 230.000 & 9.200 .000 \\
\hline 23 & 2.400 .000 & $24.000 .000)$ \\
\hline 24 & 1.600 .000 & 5.400 .000 \\
\hline 25 & 920.000 & $31.000 .0(x)$ \\
\hline 26 & 130.000 & 40.000 .000 \\
\hline
\end{tabular}

Quadro de associacũo referente à Tabela II

\begin{tabular}{|c|c|c|c|}
\hline Enterococos & - Collformes \\
\hline+ & - & + & Total \\
\hline- & 5 & 20 & 25 \\
\hline Total & 0 & 1 & 1 \\
\hline 5 & 21 & 26 \\
\hline
\end{tabular}

Resultados năo significantes ao nivel de $5 \%$ (testes monocaudal). 
Rev. Fac. Med. Vet. S. Paulo - Vol. 8 fasc. 1, 1969

TABELA III - Teor em coliformes e enterococos em QUEIJO "MINAS" DURO. (NMP/g).

\begin{tabular}{|c|c|c|}
\hline Amostra & Coliformes & Enterococos \\
\hline 1 & negativo & 9.000 .000 \\
\hline 2 & 24.000 .000 & 24.000 .000 \\
\hline 3 & 4.000 & 1.300 .000 \\
\hline 4 & negativo & 160.000 .000 \\
\hline 5 & 4.500 & 240.000 .000 \\
\hline 6 & negatlvo & 200.000 \\
\hline 7 & 2.000 & 4.900 .000 \\
\hline 8 & 4.600 & negativo \\
\hline 9 & negatlvo & 24.000 .000 \\
\hline 10 & negativo & 1.600 .000 \\
\hline 11 & 2.400 .000 & 2.400 .000 \\
\hline 12 & negatlvo & 2.400 .000 \\
\hline 13 & 1.100 .000 & 24.000 .000 \\
\hline 14 & 45.000 & 24.000 .000 \\
\hline 15 & negativo & 11.000 .000 \\
\hline 16 & 79.000 & 13.000 .000 \\
\hline 17 & negativo & 7.200 .000 \\
\hline 18 & 20.000 & 2.100 .000 \\
\hline
\end{tabular}

Quadro de assoclacão referente à Tabela III

\begin{tabular}{|c|c|c|c|}
\hline Enterococos & - & + & Total \\
\hline+ & -1 & 9 & 17 \\
- & - & 1 & 1 \\
\hline Total & 8 & 10 & 18 \\
\hline
\end{tabular}

Resultados significantes ao nivel de $5 \%$ (teste monocaudal). 
TABEIA IV -- TeOr em coliformes e enterororns em QLEIJO PRATO. (N.MP/g).

\begin{tabular}{|c|c|c|}
\hline Amostra & Collformes & Enterococos \\
\hline 1 & 2.400 .000 & 24.000 .000 \\
\hline 2 & 240.000 & 490.000 \\
\hline 3 & $2.400 .000)$ & 1.700 .000 \\
\hline 4 & negativo & $35.000 .000)$ \\
\hline 5 & 490.000 & 6.400 .000 \\
\hline 6 & 430.000 & 9.200 .000 \\
\hline 7 & 160.000 .000 & 240.000 .000 \\
\hline 8 & negativo & 180.000 \\
\hline 9 & 20.000 & 180.000 \\
\hline 10 & 19.000 & negativo \\
\hline 11 & negativo & 260.000 \\
\hline 12 & 22.000 & $24.00(0.00()$ \\
\hline 13 & 11.000 & 3.500 .000 \\
\hline 14 & negativo & 9.2011 .000 \\
\hline 15 & 2.400 .000 & 24.000 .000 \\
\hline 16 & 35.000 & 4.300 .000 \\
\hline 17 & 240.000 & 24.000 .000 \\
\hline 18 & 2.400 .000 & 24.000 .000 \\
\hline 19 & negativo & 92.000 .000 \\
\hline
\end{tabular}

Quadro de associacão referente ì Tabela IV

\begin{tabular}{|c|c|c|c|}
\hline Enterococos & - & + & Total \\
\hline+ & -5 & 18 & 18 \\
\hline- & 0 & 1 & 1 \\
\hline Total & 5 & 14 & 19 \\
\hline
\end{tabular}

Resultados significantes ao nivel de $5 \%$ (teste monoraudal). 
Rev. Fac. Med. Vet. S. Paulo - Vol. 8 fasc. 1, 1969

TABFLA $V$ - Teor em coliformes e enterococos em LEITE PASTFURIZADO TIPO "C" (NMP/g).

\begin{tabular}{|c|c|c|}
\hline Amostra & Coliformes & Enterococos \\
\hline 1 & 13.000 & 2.300 \\
\hline 2 & 200 & 17.000 \\
\hline 3 & 560 & 490 \\
\hline 4 & negativo & 78 \\
\hline 5 & negativo & negativo \\
\hline G & 450 & 11.000 \\
\hline 7 & negativo & 130 \\
\hline 8 & 330 & 3.300 \\
\hline 9 & 200 & 1.300 \\
\hline 10 & negativo & 200 \\
\hline 11 & 7.900 & 24.000 \\
\hline 12 & negatiso & 780 \\
\hline 13 & 450 & 450 \\
\hline 14 & 2.500 & 3.300 \\
\hline 15 & 3 & 680 \\
\hline 16 & negativo & 780 \\
\hline 17 & 2.300 & 2.300 \\
\hline
\end{tabular}

Quadro de associação referente à Tabela V

\begin{tabular}{|c|c|c|c|}
\hline Finterocoors & - & + & Total \\
\hline+ & 5 & 11 & 16 \\
\hline- & 1 & 0 & 1 \\
\hline Total & 6 & 11 & 17 \\
\hline
\end{tabular}

Resultados significantes a nivel (le $5 \%$ (teste monocaudal). 
TABELA VI - Teor em coliformes e enterococos em QLEIJO TIPO "MUZZaRELLA". (NMP/g).

\begin{tabular}{|c|c|c|}
\hline Amostra & Coliformes & Enterococos \\
\hline 1 & 33.000 & 170.000 \\
\hline 2 & 4.500 & 1.600 .000 \\
\hline 3 & 350.000 & 2.400 .000 \\
\hline 4 & 20.000 & negativo \\
\hline 5 & negativo & 9.200 .000 \\
\hline 6 & 240.000 & 8.100 .000 \\
\hline 7 & 45.000 & 160.000 .000 \\
\hline 8 & negativo & 28.000 .000 \\
\hline 9 & 14.000 & 22.000 .000 \\
\hline 10 & negativo & 7.000 .000 \\
\hline 11 & 4.500 & 240.000 .000 \\
\hline 12 & negativo & 20.000 \\
\hline 13 & negativo & 400.000 \\
\hline 14 & negativo & 62.000 \\
\hline 15 & negativo & 61.000 \\
\hline 16 & negativo & 220.000 \\
\hline 17 & negativo & 2.400 .000 \\
\hline 18 & negativo & 24.000 .000 \\
\hline 19 & negativo & 16.000 .000 \\
\hline
\end{tabular}

Quadro de assoclaçăo referente à Tabela VI

\begin{tabular}{|c|c|c|c|}
\hline Coliformes & - & + & Total \\
\hline+ & -11 & 7 & 18 \\
\hline- & 0 & 1 \\
\hline Total & 11 & 8 & 19 \\
\hline
\end{tabular}

Resultados significantes ao nivel de $5 \%$ (teste monoraudal). 
Rev. Fac. Med. Vet. S. Paulo - Vol. 8 fasc. 1, 1969

TABEIA VII - Teor em coliformes e enterococos em LEITF. FM PO INTEGRAL. (NMP,g).

\begin{tabular}{|c|c|c|}
\hline Amostra & Coliformes & Enterococos \\
\hline 1 & negativo & 23.000 \\
\hline 2 & negativo & negativo \\
\hline 3 & negativo & negativo \\
\hline 4 & negativo & 233.000 \\
\hline 5 & negativo & 2.833 \\
\hline 6 & negativo & 11.477 \\
\hline 7 & negativo & 3.450 \\
\hline 8 & negativo & 2.349 \\
\hline 9 & negativo & 1.466 \\
\hline 10 & negativo & 3.416 \\
\hline 11 & negativo & 477 \\
\hline 12 & negativo & 383 \\
\hline 13 & negatlvo & 24.000 \\
\hline 14 & negatlvo & $\mathbf{3 . 3 5 0}$ \\
\hline 15 & negativo & 7.900 \\
\hline 16 & negativo & 1.000 \\
\hline 17 & negativo & 400 \\
\hline 18 & negativo & 66 \\
\hline 19 & negatlvo & 24.000 \\
\hline 20 & negativo & 24.000 \\
\hline 21 & negativo & 35.000 \\
\hline 22 & negatlyo & 13.300 \\
\hline 23 & negativo & 24.0000 \\
\hline 24 & negativo & $24.0(10)$ \\
\hline 25 & negatjvo & 200 \\
\hline 26 & negativo & 30.000 \\
\hline 27 & negativo & 16.000 \\
\hline 28 & negativo & 160.000 \\
\hline 29 & negatlvo & 13.000 \\
\hline 30 & negativo & 16.000 \\
\hline 31 & negativo & 1.600 .000 \\
\hline 32 & negativo & 24.000 \\
\hline
\end{tabular}

Quadro de associacão referente a Tabela VII

\begin{tabular}{|r|r|r|r|}
\hline Cnterociocos & - & + & Total \\
\hline Total & -30 & & 30 \\
\hline+ & -2 & 0 & 2 \\
\hline- & 32 & 0 & 32 \\
\hline
\end{tabular}

Resultados significantes an nivel de $5 \%$ (teste mono(anudal). 
TABELA VIII - TeOr em coliformes e enterococos em I.FITH: FMI PO I)FSNATADO). (NMP: (马).

\begin{tabular}{|c|c|c|}
\hline Amostra & Coliformes & Enterococos \\
\hline 1 & negativo & 450 \\
\hline 2 & negativo & $\times 33$ \\
\hline 3 & negativo & 1.850 \\
\hline 4 & negativo & $2.926 j$ \\
\hline 5 & negativo & 7.900 \\
\hline 6 & negativo & 24.000 \\
\hline 7 & negativo & $54 .(x) 0$ \\
\hline 8 & negativo & .190 \\
\hline 9 & negativo & 400 \\
\hline 10 & negativo & 24.000 \\
\hline 11 & negattio & 24.000 \\
\hline 12 & negativo & $8.0(0)$ \\
\hline 1.3 & negativo & 24.000 \\
\hline 14 & negativo & 2.300 \\
\hline 15 & negativo & $1.90(x)$ \\
\hline 16 & negativo & 3.100 \\
\hline 17 & nefativo & 3.500 \\
\hline 18 & negativo & $1.7(10)$ \\
\hline 19 & negativo & 900 \\
\hline 20 & negativo & 1.300 \\
\hline 21 & negativo & 150 \\
\hline 22 & negativo & 18 \\
\hline 23 & negativo & 230 \\
\hline
\end{tabular}

Quadro de assoriaçăo referente à Iabela VII

\begin{tabular}{|c|c|c|c|}
\hline Enterococos & - & & Total \\
\hline+ & 23 & 0 & 23 \\
\hline- & 0 & 0 & 0 \\
Total & 23 & 0 & 23 \\
\hline
\end{tabular}

Resultados significantes an mive! de $5 \%$ (teste monocaudall. 
TABEIAA IX - Teor em coliformes e coterocoros em QCFIJO TIPO "PARMFZRO". (NMP")

\begin{tabular}{|c|c|c|}
\hline Amostra & Colirormes & Enterococos \\
\hline 1 & 20.000 & $2 \cdot 1.000 .000$ \\
\hline 2 & negativo & 24.000 .000 \\
\hline 3 & negativo & 24.000 .000 \\
\hline 4 & negativo & 70.000 \\
\hline 5 & negativo & 24.000 .000 \\
\hline 6 & negativo & 191.000 \\
\hline 7 & negativo & 128.550 \\
\hline 8 & negativo & $9 .(10) 0$ \\
\hline 9 & negativo & 1.6300 .000 \\
\hline 10 & negativo & 11.800 .000 \\
\hline 11 & negativo & 9.900 .000 \\
\hline 12 & negativo & 570.000 \\
\hline 13 & negativo & 33.000 \\
\hline 1.4 & 100 & 2.400 .000 \\
\hline 15 & negrativo & $2 \cdot 10.000$ \\
\hline 16 & negativo & 2.8010 \\
\hline 17 & 79.000 & 13.000 .000 \\
\hline 18 & negativo & 49.000 \\
\hline 19 & negativo & 2.100 .000 \\
\hline 20 & negativo & $320 .(000)$ \\
\hline 21 & negativo & 560.000 \\
\hline
\end{tabular}

Quadro de associaçăo referente à Tabela IX

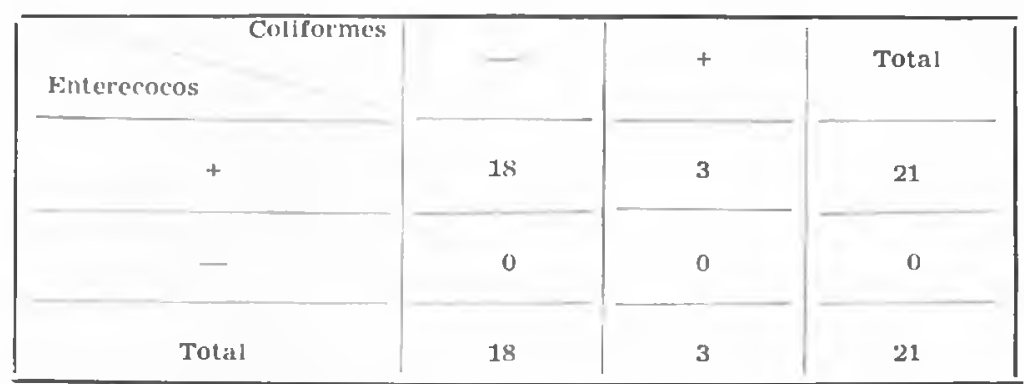

Resultados signiricantes ao nivel de $5 \%$ (teste monocaudal). 